\title{
Cost-utility analysis of 21-gene assay for node-positive early breast cancer
}

\author{
L. Masucci MSc, ${ }^{*}$ S. Torres MD, ${ }^{\dagger}$ A. Eisen MD, ${ }^{\dagger \neq}$ M. Trudeau MD, ${ }^{\dagger \neq}$ I. Tyono BSc Pharm, ${ }^{\dagger}$ H. Saunders MSc, ${ }^{*}$ \\ K.W. Chan $\mathrm{MD} \mathrm{PhD}^{\dagger \neq \S}$ and W. Isaranuwatchai $\mathrm{PhD}^{* \S \|}$
}

\begin{abstract}
Background For women with lymph node (LN)-positive, estrogen receptor-positive, and HER2 (human epidermal growth factor receptor 2)-negative breast cancer (вса), current guidelines recommend treatment with both hormonal therapy and chemotherapy. The 21-gene Recurrence Score (Rs) assay might be helpful in selecting patients with вCa who can be spared chemotherapy when they have 1-3 positive LNS and a lower risk of recurrence. In the present study, we performed a cost-utility analysis comparing use of the 21-gene Rs assay with current practice from the perspective of a Canadian health care payer.
\end{abstract}

Methods A Markov model was developed to determine costs and quality-adjusted life-years (QALYs) over a patient's lifetime. Patient outcomes in both study groups were examined based on published clinical trials. Costs were derived primarily from published Canadian sources. Costs and outcomes were discounted at $1.5 \%$ annually, and costs are reported in 2016 Canadian dollars. A probabilistic analysis was used, and the model parameters were varied in a sensitivity analysis.

Results The results indicate that use of the 21-gene Rs assay was less costly ( $\$ 432$ less) and more effective $(0.22$ QALYS) than current practice. The probabilistic analysis revealed that $70 \%$ of the 10,000 simulated incremental costeffectiveness ratios were in the southeast quadrant. The results were sensitive to the probability of a low Rs and to the probability of receiving chemotherapy in the low-risk Rs category and in current practice.

Conclusions Use of the 21-gene Rs assay could be a cost-effective strategy for Ontario patients with estrogen receptor-positive, HER2-negative early BCa and 1-3 positive LNS.

Key Words Cost-effectiveness, breast cancer, 21-gene assay, chemotherapy

Curr Oncol. 2019 October;26(5):307-318

www.current-oncology.com

\section{INTRODUCTION}

Breast cancer (вса) is the most common cancer and the 2nd leading cause of death from cancer among Canadian women ${ }^{1}$. For women with lymph node (LN)-positive, estrogen receptor (ER)-positive BCa, current guidelines recommend treatment with both hormonal therapy and chemotherapy $^{2,3}$. In ER-positive disease, the addition of adjuvant chemotherapy to tamoxifen reduces the risk of вса recurrence by approximately $30 \%$ and the risk of вса mortality by approximately $20 \%$.

The 21-gene Recurrence Score (Rs) assay is a genomic test used in determining the likelihood of chemotherapy benefit after surgical treatment for early-stage вса ${ }^{4}$. Раtients are defined as having a high ( $\mathrm{RS} \geq 31$ ), intermediate (RS $=18-30)$, or low $(\mathrm{RS}<18)$ risk of distant recurrence. The 21-gene Rs assay might be helpful in selecting patients with a lower risk of recurrence, for whom chemotherapy could be omitted. It is routinely used to guide adjuvant treatment decisions in patients with node-negative вca.

The clinical utility of the Rs assay has also been demonstrated in studies involving LN-positive patients ${ }^{4-7}$. A growing body of evidence is showing that the Rs assay can lead to tailored treatment by sparing patients with 1-3 positive LNS and a low RS unnecessary chemotherapy that could be associated with an increased risk of toxicity 
and a reduction in health-related quality of life ${ }^{8}$. In addition, tailored treatment might save the health care system unnecessary drug and administration costs, and the costs associated with complications ${ }^{9}$.

Studies have shown that the 21-gene Rs assay might be a cost-effective option for patients with LN-negative, ER-positive вса ${ }^{10-13}$. A few studies ${ }^{9,14-16}$ have also examined the cost-effectiveness of the 21-gene Rs assay in patients with LN-positive, ER-positive BCa and have shown that it might be a cost-effective option.

Currently in Ontario, the most populous province in Canada, theassayis reimbursed by the publiclyfundedhealth care system only for LN-negative and micrometastatic LNpositive early-stage вса. In the present study, we performed a cost-utility analysis of the 21-gene Rs assay compared with current practice (no Rs assay) for patients with LNpositive (1-3 positive LNS), ER-positive, and HER2 (human epidural growth factor receptor 2)-negative early вса from the perspective of the Ontario Ministry of Health and Long-Term Care.

\section{METHODS}

\section{Model Structure}

Using the TreeAge Pro 2014 software application (TreeAge Software, Williamstown, MA, U.S.A.), a Markov model with yearly cycle lengths (Figure 1) was developed to compare the 21-gene Rs assay with current practice in terms of lifetime clinical consequences [quality-adjusted life-years (QALYS)] and economic consequences (cost). The model simulated a cohort of patients 60 years of age diagnosed with LN-positive (1-3 positive LNs), ER-positive, HER2-negative early вса. The starting age of 60 years was chosen because that is the median age of patients with вса in Canada (clinical expert opinion, 2018).

Patients in the 21-gene Rs assay strategy were stratified into 3 categories: low risk ( $\mathrm{RS}<18)$, intermediate risk $(\mathrm{RS}=18-30)$, and high risk ( $\mathrm{RS} \geq 31)$ of recurrence. Patients in the high-risk category started in one of three chemotherapy health states: chemotherapy with no toxicities; chemotherapy with febrile neutropenia; or chemotherapy with nausea and vomiting. Patients in the chemotherapy health states could move to these health states: disease free

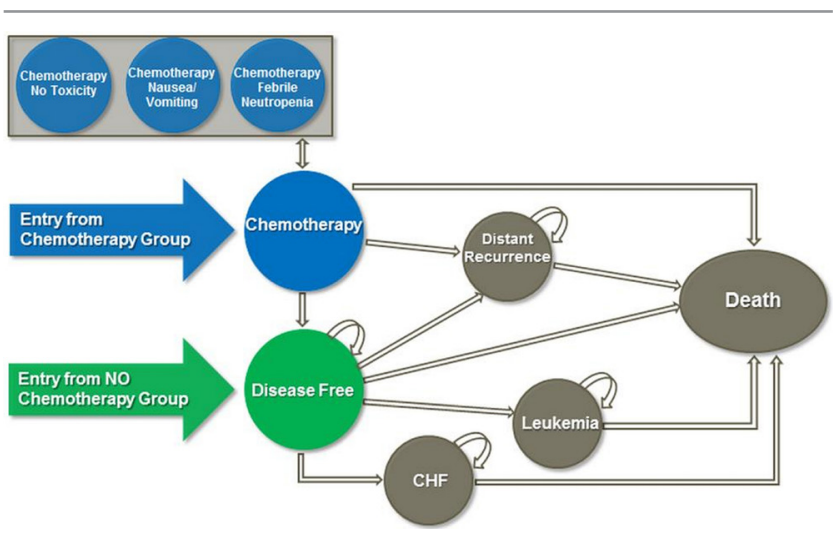

FIGURE 1 Markov model used for the analysis. $\mathrm{CHF}=$ congestive heart failure. without recurrence, distant recurrence, or death. Patients who received chemotherapy could also go on to develop congestive heart failure (CHF) or leukemia 1-7 years after treatment. Of patients in the intermediate-risk category, $52 \%$ received adjuvant chemotherapy and started in one of the three chemotherapy health states (Table I) ${ }^{7}$. Those who did not receive chemotherapy (48\%) started in the disease-free health state. All patients in the low-risk category did not receive adjuvant chemotherapy and started in the disease-free health state, where they received tamoxifen for 5 years, followed by aromatase inhibitors for another 5 years. From the disease-free without recurrence health state, patients could remain in that health state, develop distant recurrence, or die. In the distant recurrence health state, patients stayed in that health state until death. All patients in the model eventually died from Bca or background mortality. A lifetime horizon was taken, and future costs and benefits were discounted at $1.5 \%$ annually based on guidelines from the Canadian Agency for Drugs and Technologies in Health ${ }^{28}$.

\section{Clinical Input Data}

The proportion of patients assigned to each risk category based on the 21-gene Rs assay was obtained from a prospective study that evaluated the effect of the assay on treatment decisions for women with LN-positive early вса in Ontario (Table I) ${ }^{7}$. A phase III randomized controlled trial (swog-8814) found that the Rs was a prognostic factor for disease-free survival in patients with LN-positive, ER-positive $\mathrm{BCa}^{25}$. Because recurrence-free survival was not available in swoG-8814, we used its reported disease-free survival, which consisted of time to death, recurrence, or new primary cancer. We made an assumption that a large proportion of events were related to recurrence rather than to death or a new primary cancer. To calculate the annual probability of distant recurrence, we fitted a Weibull distribution to Kaplan-Meier curves for each Rs category in the tamoxifen-only group (that is, no chemotherapy) and calculated an annual probability of recurrence ${ }^{29}$. To obtain the risk of distant recurrence with chemotherapy for each risk group, we applied the hazard ratios from swoG-8814 $(\text { Table } \mathrm{I})^{25}$. For patients in the current-practice strategy, we estimated the weighted average risk of recurrence with and without adjuvant chemotherapy in the 3 Rs categories.

Once patients developed distant recurrence, it was assumed that the transitional probability for вса death was the same for all patients regardless of Rs classification. Based on clinician input, we also assumed that all patients would die after year 20 in that health state (clinical expert opinion, 2018). We accounted for background mortality using Canadian life tables from Statistics Canada ${ }^{27}$.

\section{Chemotherapy Assignment and Toxicities}

For patients in the 21-gene Rs assay strategy, the proportion receiving chemotherapy was obtained from the post-Rs-test treatment recommendations of oncologists in an Ontario study ${ }^{7}$ Patients in all Rs categories were given hormonal treatment with tamoxifen for 5 years, followed by an aromatase inhibitor (letrozole) for another 5 years. Patients who received adjuvant chemotherapy started tamoxifen after chemotherapy completion. 
TABLE I Annual transition probabilities

\begin{tabular}{|c|c|c|c|c|}
\hline \multirow[t]{2}{*}{ Parameter } & \multicolumn{2}{|c|}{ Probability value } & \multirow[t]{2}{*}{ Distribution } & \multirow[t]{2}{*}{ Source } \\
\hline & Base case & Sensitivity analyses ${ }^{a}$ & & \\
\hline \multicolumn{5}{|c|}{ Proportion of patients assigned to each risk category } \\
\hline Low-risk RS $(<18)$ & 0.57 & $0.39-0.63$ & Dirichlet & \\
\hline Intermediate-risk RS (18-30) & 0.34 & $0.28-0.37$ & Dirichlet & Torres et al., $2018^{7}$ \\
\hline High-risk RS ( $\geq 31)$ & 0.09 & $0.08-0.32$ & Dirichlet & \\
\hline \multicolumn{5}{|l|}{ CTx assignment for RS strategy } \\
\hline \multicolumn{5}{|l|}{ High-risk RS ( $\geq 31)$} \\
\hline CTx & 1.0 & $0.60-1.0$ & Fixed & Torres et al., $2018^{7}$ \\
\hline FEC-D & 0.70 & $0.63-0.77$ & Fixed & Clinical expert opinion, \\
\hline dd AC-T & 0.30 & $0.27-0.33$ & Fixed & 2018 \\
\hline \multicolumn{5}{|l|}{ Intermediate-risk RS (18-30) } \\
\hline CTx & 0.52 & $0.47-0.55$ & Fixed & Torres et al., $2018^{7}$ \\
\hline $\mathrm{TC}$ & 1.0 & $0.90-1.0$ & Fixed & Clinical expert opinion, 2018 \\
\hline \multicolumn{5}{|c|}{ CTx assignment for the current-practice strategy } \\
\hline CTx & 0.79 & $0.64-0.87$ & Fixed & $\begin{array}{l}\text { Torres et al. 20187, } \\
\text { Hannouf et al., 2014 }\end{array}$ \\
\hline FEC-D & 0.44 & $0.40-0.48$ & Fixed & \\
\hline $\mathrm{TC}$ & 0.45 & $0.40-0.50$ & Fixed & Torres et al., $2018^{7}$ \\
\hline ddAC-T & 0.11 & $0.10-0.12$ & Fixed & \\
\hline \multicolumn{5}{|l|}{ CTx toxicities } \\
\hline \multicolumn{5}{|l|}{ FEC-D } \\
\hline Febrile neutropenia & 0.09 & $0.04-0.19$ & Beta & Younis et al., $2012^{17}$ \\
\hline Nausea or vomiting & 0.11 & $0.10-0.12$ & Beta & Roche et al., $2006^{18}$ \\
\hline Death from toxicity & 0.01 & $0.005-0.036$ & Beta & Younis et al., $2012^{17}$ \\
\hline Congestive heart failure & 0.005 & $0.0045-0.0055$ & Beta & Goldhar et al., $2016^{19}$ \\
\hline Leukemia & 0.0008 & $0.0007-0.0009$ & Beta & Torres et al., $2015^{20}$ \\
\hline \multicolumn{5}{|l|}{$\mathrm{TC}$} \\
\hline Febrile neutropenia & 0.07 & $0.046-0.099$ & Beta & Younis et al., $2012^{17}$ \\
\hline Nausea or vomiting & 0.02 & $0.018-0.022$ & Beta & Jones et al., 2009²1 \\
\hline Death from toxicity & 0.01 & $0.005-0.036$ & Beta & Younis et al., $2012^{17}$ \\
\hline \multicolumn{5}{|l|}{ ddAC-T } \\
\hline Febrile neutropenia & 0.02 & $0.018-0.022$ & Beta & Torres et al., $2015^{20}$ \\
\hline Nausea or vomiting & 0.05 & $0.045-0.05$ & Beta & Citron et al., $2003^{22}$ \\
\hline Death from toxicity & 0.001 & $0.0009-0.01$ & Beta & Torres et al., $2015^{20}$ \\
\hline Congestive heart failure & 0.005 & $0.0045-0.0055$ & Beta & Goldhar et al., $2016^{19}$ \\
\hline Leukemia & 0.003 & $0.0027-0.0033$ & Beta & Torres et al., $2015^{20}$ \\
\hline \multicolumn{5}{|l|}{ Probability of death from ... } \\
\hline \multicolumn{5}{|l|}{ Congestive heart failure } \\
\hline Year 1 & 0.13 & & Fixed & \\
\hline Year 2 & 0.22 & & Fixed & Frazier et al., $2007^{23}$ \\
\hline Year 3 onward & 0.31 & & Fixed & \\
\hline
\end{tabular}


TABLE I Continued

\begin{tabular}{lcc}
\hline Parameter & Probability value & Distribution Source \\
\cline { 2 - 3 } & Base case Sensitivity analyses & \\
\hline
\end{tabular}

Probability of death from ... Continued

Leukemia

$\begin{array}{llll}\text { Year } 1 & 0.73 & \text { Fixed } \\ \text { Year } 2 & 0.84 & \text { Fixed } & \text { Hulegardh et al., } 2015^{24} \\ \text { Year } 3 \text { onward } & 0.90 & \text { Fixed }\end{array}$

\begin{tabular}{|c|c|c|c|c|}
\hline \multicolumn{5}{|c|}{$\begin{array}{l}\text { Annual probability of recurrence for those not treated } \\
\text { with CTx (tamoxifen alone) }\end{array}$} \\
\hline Low-risk RS (<18) & 0.0312 & $0.0281-0.0343$ & Fixed & \multirow{3}{*}{$\begin{array}{l}\text { Estimated from } \\
\text { Albain et al., } 2010^{25}\end{array}$} \\
\hline Intermediate-risk RS (18-30) & 0.0656 & $0.0590-0.0722$ & Fixed & \\
\hline High-risk RS ( $\geq 31)$ & 0.0949 & $0.0854-0.1044$ & Fixed & \\
\hline
\end{tabular}

HR for recurrence with the use of CTx

$\begin{array}{llll}\text { Low-risk RS }(<18) & 1.00 & \text { Fixed } & \text { Clinical experts } \\ \text { Intermediate-risk RS (18-30) } & 0.72 & \text { Fixed } & \text { Albain et al., } 2010^{25} \\ \text { High-risk RS }(\geq 31) & 0.59 & \text { Fixed }\end{array}$

Annual probability of recurrence

for those treated with CTx

$\begin{array}{lllll}\text { Low-risk RS }(<18) & 0.0312 & 0.0281-0.0343 & \text { Fixed } & \begin{array}{c}\text { Calculated based } \\ \text { on HR for recurrence } \\ \text { with the use of CTx }\end{array}\end{array}$

High-risk RS $(\geq 31)$

$0.0571 \quad 0.0514-0.0628 \quad$ Fixed

with the use of CTx

Annual probability of recurrence for

those in the current-practice strategy

$\begin{array}{lllll}\text { Without CTx } & 0.0486 & 0.0437-0.0535 & \text { Fixed } & \text { Clinical expert opinion, } \\ \text { With CTx } & 0.0391 & 0.0352-0.0430 & \text { Fixed } & 2018, \text { weighted average }\end{array}$

Death from distant recurrence
$\begin{array}{lcccc}\text { Years } 1-20 & 0.17 & 0.15-0.19 & \text { Fixed } & \text { Mouridsen et al. 200326 } \\ \text { Year } 20 \text { onward } & 1 & \text { Fixed } & \text { Clinical expert opinion, } 2018\end{array}$

Background mortality

Life tables

Fixed

Statistics Canada, $2011^{27}$

a Ranges used in the sensitivity analyses were, for the most part, $\pm 10 \%$ of the base case. Where available, additional literature was used for the sensitivity analysis ranges. As a result, some values have wide ranges.

RS = Recurrence Score (Oncotype DX: Genomic Health, Redwood City, CA, U.S.A.); CTx = chemotherapy; FEC-D = 5-fluorouracil-epirubicincyclophosphamide, followed by docetaxel; dd AC-T = dose-dense doxorubicin-cyclophosphamide, followed by paclitaxel; $\mathrm{TC}=$ docetaxelcyclophosphamide.

Based on clinical opinion, $70 \%$ of those in the highrisk Rs category received 6 cycles of FEC-D: 3 cycles of 5 -fluorouracil $500 \mathrm{mg} / \mathrm{m}^{2}$, epirubicin $100 \mathrm{mg} / \mathrm{m}^{2}$, and cyclophosphamide $500 \mathrm{mg} / \mathrm{m}^{2}$, followed by 3 cycles of docetaxel $100 \mathrm{mg} / \mathrm{m}^{2}$ (clinical expert opinion, 2018). The remaining $30 \%$ received 8 cycles of ddAC-T: 4 cycles of doxorubicin $60 \mathrm{mg} / \mathrm{m}^{2}$ and cyclophosphamide $600 \mathrm{mg} / \mathrm{m}^{2}$, followed by 4 cycles of paclitaxel $175 \mathrm{mg} / \mathrm{m}^{2}$. For patients assigned to the intermediate-risk Rs category, $52 \%$ received chemotherapy. All patients in that category who received chemotherapy were treated with 4 cycles of Tc chemotherapy (docetaxel $75 \mathrm{mg} / \mathrm{m}^{2}$ and cyclophosphamide
$600 \mathrm{mg} / \mathrm{m}^{2}$ ). All patients treated with adjuvant chemotherapy received $300 \mu \mathrm{g}$ of filgrastim daily (clinical expert opinion, 2018). As well, patients in all chemotherapy health states received zoledronic acid every 6 months for 3 years. For patients in the current-practice strategy, the proportion receiving chemotherapy and the type of chemotherapy regimen assigned were obtained from the pre-Rs-test treatment recommendations of oncologists in an Ontario study (Table I) ${ }^{7}$.

Four different types of chemotherapy toxicities were considered: febrile neutropenia, nausea and vomiting, $\mathrm{CHF}$, and leukemia. Febrile neutropenia and nausea and 
vomiting could occur during treatment. The probability of febrile neutropenia while receiving FEC-D or TC and granulocyte colony-stimulating factor was obtained from a meta-analysis ${ }^{17}$. The probability of febrile neutropenia while on ddAC-T was obtained from an Ontario study ${ }^{20}$. The probability of a patient experiencing nausea and vomiting was obtained from the respective clinical trials for each of the treatments ${ }^{18,21,22}$.

Congestive heart failure and leukemia are chemotherapy toxicities that can occur after treatment. Patients treated with FEC-D and ddAC-T are at risk for those toxicities because of their anthracycline content. The proportions of patients experiencing leukemia, by treatment type, and experiencing CHF were obtained from two studies that used Ontario population data ${ }^{20}$. The proportion of patients experiencing cHF was obtained from a study examining the risk of heart failure associated with adjuvant trastuzumab in patients with вса $^{19}$. The probability of experiencing CHF that we used was the same for both FEC-D and ddAC-T. The risk of death from cHF for years 1-3 was obtained from a study that provided the Kaplan-Meier probabilities of survival for women with non-ischemic stroke over 4 years ${ }^{23}$. Afterward, a constant probability of death was assumed. The probability of death associated with leukemia from years 1-3 was taken from a study that examined patients with treatment-related secondary acute myeloid leukemia in Sweden ${ }^{24}$. After year 3, a constant probability of death was assumed.

\section{Utilities}

The utility values (Table iI) associated with the various health states ${ }^{30}$ and the chemotherapy toxicities came from various published sources and were derived using a variety of methods ${ }^{17,31,32,37}$.

\section{Costs}

Costs were obtained from various sources (Table II). To obtain a total cost for filgrastim for each chemotherapy regimen, we assumed that $50 \%$ of patients would receive filgrastim type 1 and the other $50 \%$ would receive filgrastim type 2 (Sunnybrook Health Sciences Centre database, 2017).

Each chemotherapy regimen was associated with a different quality-based procedure band for systemic therapy, which included the cost of nursing and pharmacy time (Sunnybrook Health Sciences Centre database, 2017). We also included the costs of a physician consultation (fee code A445), medical-specific assessment (fee code A444), and partial assessment (fee code A448) for each chemotherapy regimen ${ }^{35}$. Lastly, we included the cost of a peripherally inserted central catheter and technologist for each chemotherapy regimen (\$376) (Sunnybrook Health Sciences Centre database, 2017).

The costs of ongoing care for the patients who were disease-free (that is, recurrence-free) and the costs of treating distant recurrence were obtained from a Canadian study that estimated the health care costs associated with the lifetime management of women diagnosed with вса $^{33}$. The cost averaged for all stages of вса was used. Costs for treating distant recurrence might be underestimated given that costs have increased with the introduction of cyclin-dependent kinase 4/6 inhibitors in the treatment of those patients.

The costs associated with chemotherapy toxicities were obtained from a variety of published sources (Table $\mathrm{II}^{36}$. We assumed that a patient could experience, at most, 1 episode of febrile neutropenia during chemotherapy (clinical expert opinion, 2018) and that nausea and vomiting happen after each chemotherapy cycle and last for 1 week. The costs of nausea and vomiting therefore differed with the chemotherapy regimen (clinical expert opinion, 2018). The costs associated with leukemia came from a Canadian study that examined the cost of cancer by phase of care. The analysis included the direct health care costs for the initial phase of cancer (that is, the first year after the cancer diagnosis) for patients who survived beyond year $1^{39}$. Lastly, the costs associated with cHF were obtained from a cost-effectiveness study ${ }^{38}$. All costs were inflated to 2016 Canadian dollars using the Consumer Price Index for health care services in Ontario ${ }^{40}$.

\section{Analysis}

We estimated an incremental cost-effectiveness ratio (ICER) representing the incremental cost for 1 QALY gained with use of the 21-gene Rs assay instead of current practice. We also estimated an incremental cost per life-year gained. For the base case, a probabilistic analysis was conducted to assess the uncertainty of all parameters. We used a Dirichlet distribution for multinomial data, gamma distributions for costs, and beta distributions for probabilities and utilities. All parameters were randomly sampled from their assigned distributions and 10,000 simulations were performed. We estimated the likelihood of each strategy being more favourable across a range of willingness-to-pay thresholds using cost-effectiveness acceptability curves. The results were also summarized on a cost-effectiveness plane. A deterministic 1-way sensitivity analysis was conducted on all key model parameters (such as the probability of recurrence with chemotherapy and the Rs stratification).

\section{Validation}

The model structure and outcomes were evaluated. For each Rs category, we obtained the proportion of deaths attributable to CHF, leukemia, distant recurrence, short-term toxicity, and background mortality. Those estimates were shown to clinician experts to determine whether they were in line with clinical practice (supplementary Tables I and II).

\section{RESULTS}

The results indicated that the 21-gene Rs strategy dominated current practice. The 21-gene Rs strategy was less costly (\$432 less) and more effective (0.22 QALYs) than current practice over a lifetime horizon (Table III). In addition, 0.17 life-years were gained with the 21-gene Rs assay strategy.

The probabilistic analysis revealed that $70 \%$ of the 10,000 simulated ICERs were located in the southeast quadrant, meaning that the 21-gene Rs assay strategy was less costly and more effective than current practice (Figure 2). If 1 QALY gained was valued at $\$ 50,000$, then $95 \%$ of the simulated ICERS were considered cost-effective (Figure 3). 
TABLE II Utilities and annual cost estimates for tests, medications, and health states

\begin{tabular}{|c|c|c|c|c|}
\hline \multirow[t]{2}{*}{ Parameter } & \multicolumn{2}{|c|}{ Estimated value } & \multirow[t]{2}{*}{ Distribution } & \multirow[t]{2}{*}{ Source } \\
\hline & Base case & Sensitivity analyses & & \\
\hline \multicolumn{5}{|l|}{ Utilities } \\
\hline Year 1 after Dx, hormone therapy & 0.74 & $0.67-0.81$ & Beta & \multirow{4}{*}{ Lidgren et al., $2007^{30}$} \\
\hline Year 1 after Dx, CTx & 0.62 & $0.56-0.68$ & Beta & \\
\hline Year 2 onward, either treatment & 0.78 & $0.74-0.81$ & Beta & \\
\hline Distant recurrence & 0.69 & $0.62-0.73$ & Beta & \\
\hline Congestive heart failure & 0.53 & $0.48-0.58$ & Beta & Kirsch et al., $2000^{31}$ \\
\hline Leukemia & 0.26 & $0.23-0.29$ & Fixed & Barr et al., $1996^{32}$ \\
\hline Febrile neutropenia & 0.62 & $0.56-0.68$ & Fixed & \multirow{2}{*}{ Clinical expert opinion, 2018} \\
\hline Nausea or vomiting & 0.62 & $0.56-0.68$ & Fixed & \\
\hline 21-Gene RS assay (\$) & 5,177 & $4,659-5,695$ & Fixed & Genomic Health Ltd. ${ }^{a}$ \\
\hline \multicolumn{5}{|l|}{ Ongoing care for disease-free patients (\$) } \\
\hline Years 1 and 2 & 1,538 & $1,384-1,692$ & Gamma & \multirow{3}{*}{ Will et al., $2000^{33}$} \\
\hline Years 3 and 4 & 1,138 & $1,024-1,252$ & Gamma & \\
\hline Year 5 onward & 924 & $832-1,016$ & Gamma & \\
\hline \multicolumn{5}{|l|}{ Treating distant recurrence $(\$)$} \\
\hline Initial cost (one-time cost) & 10,314 & $9,283-11,345$ & Gamma & Will et al., $2000^{33}$ \\
\hline Ongoing care & 8,703 & $7,833-9,573$ & & Will et al., $2000^{33}$ \\
\hline End of life care (last 12 months of life) & 19,894 & $17,905-21,883$ & Gamma & de Oliveria et al., $2016^{34}$ \\
\hline Cost of tamoxifen (20 mg daily) & 176 & 158-194 & Fixed & \multirow{3}{*}{$\begin{array}{c}\text { Sunnybrook } \\
\text { Health Sciences } \\
\text { Centre database, } 2017\end{array}$} \\
\hline Cost of letrozole (2.5 mg daily) & 575 & $518-633$ & Fixed & \\
\hline Cost of zoledronic acid (intravenous) & 21 & 19-23 & Fixed & \\
\hline Cost of CTx (\$ per regimen) & & & Fixed & \\
\hline \multicolumn{5}{|l|}{ FEC-D (6 cycles) } \\
\hline 5-Fluouracil $\left(500 \mathrm{mg} / \mathrm{m}^{2}\right)$ & 6.47 & & & \\
\hline Epirubicin $(100$ mg/m²) & 109 & & & \\
\hline Cyclophosphamide (500 mg/m²) & 176 & & & \\
\hline Docetaxel $(100$ mg/m²) & 275 & & & \\
\hline FEC-D total & 566 & $509-523$ & & \\
\hline Filgrastim type 1 & 6,484 & & & \\
\hline Filgrastim type 2 & 7,770 & & & \\
\hline Filgrastim total for FEC-D ${ }^{b}$ & 7,127 & $6,414-7,840$ & & \\
\hline \multicolumn{5}{|l|}{ TC (4 cycles) } \\
\hline Docetaxel $\left(75 \mathrm{mg} / \mathrm{m}^{2}\right)$ & 275 & & & Sunnvbrook \\
\hline Cyclophosphamide $(600$ mg/m²) & 281 & & & Health Sciences \\
\hline TC total & 556 & $500-612$ & & Centre database, 2017 \\
\hline Filgrastim type 1 & 4,935 & & & \\
\hline Filgrastim type 2 & 5,914 & & & \\
\hline Filgrastim total for $\mathrm{TC}^{\mathrm{b}}$ & 5,425 & $4,883-5,968$ & & \\
\hline \multicolumn{5}{|l|}{ ddAC-T (8 cycles) } \\
\hline Doxorubicin $\left(60 \mathrm{mg} / \mathrm{m}^{2}\right)$ & 72 & & & \\
\hline Cyclophosphamide $(600$ mg/m²) & 281 & & & \\
\hline Paclitaxel $(175$ mg/m²) & 143 & & & \\
\hline ddAC-T total & 496 & $446-546$ & & \\
\hline Filgrastim type 1 & 9,870 & & & \\
\hline Filgrastim type 2 & 11,829 & & & \\
\hline Filgrastim total for dd AC- $\mathrm{T}^{\mathrm{b}}$ & 10,850 & $9,765-11,935$ & & \\
\hline
\end{tabular}


TABLE II Continued

\begin{tabular}{|c|c|c|c|c|}
\hline \multirow[t]{2}{*}{ Parameter } & \multicolumn{2}{|c|}{ Estimated value } & \multirow[t]{2}{*}{ Distribution } & \multirow[t]{2}{*}{ Source } \\
\hline & Base case & Sensitivity analyses & & \\
\hline Cost of care associated with CTx & & & Fixed & \\
\hline \multicolumn{5}{|l|}{ FEC-D } \\
\hline Nursing and pharmacy time & 1,587 & & & \\
\hline Physician visits & 463 & & & \\
\hline PICC line & 376 & & & \\
\hline FEC-D total & 2,426 & $2,184-2,669$ & & \\
\hline $\mathrm{TC}$ & & & & $\begin{array}{c}\text { Sunnybrook } \\
\text { Health Sciences }\end{array}$ \\
\hline Nursing and pharmacy time & 1,587 & & & Centre database, 2017 \\
\hline Physician visits & 340 & & & and Ontario \\
\hline PICC line & 376 & & & Physician Services ${ }^{35}$ \\
\hline TC total & 2,303 & $2,073-2,534$ & & \\
\hline \multicolumn{5}{|l|}{ ddAC-T } \\
\hline Nursing and pharmacy time & 2,517 & & & \\
\hline Physician visits & 449 & & & \\
\hline PICC line & 376 & & & \\
\hline ddAC-T total & 3,342 & $3,008-3,676$ & & \\
\hline \multicolumn{5}{|l|}{ Costs of CTx toxicities } \\
\hline Febrile neutropenia & 7,905 & $7,115-8,696$ & Gamma & Lathia et al., $2010^{36}$ \\
\hline Nausea or vomiting & & & Fixed & Lachaine et al., $2005^{37}$ \\
\hline FEC-D & 3,378 & $3,040-3,716$ & & \\
\hline ddAC-T & 4,981 & $4,483-5,479$ & & \\
\hline $\mathrm{TC}$ & 2,492 & $2,243-2,741$ & & \\
\hline Congestive heart failure & 20,719 & $18,647-22,791$ & Gamma & Younis et al., $2011^{38}$ \\
\hline Leukemia & 34,530 & $31,077-37,983$ & Gamma & De Oliveria et al., $2013^{39}$ \\
\hline
\end{tabular}

In 2017.

b Filgrastim type 1, 0.50; filgrastim type 2, 0.50 .

Dx = diagnosis; RS = Recurrence Score (Oncotype DX: Genomic Health, Redwood City, CA, U.S.A.); CTx = chemotherapy; FEC-D = 5-fluorouracilepirubicin-cyclophosphamide, followed by docetaxel; TC = docetaxel-cyclophosphamide; dd AC-T = doxorubicin-cyclophosphamide, followed by paclitaxel; PICC = peripherally inserted central catheter.

The tornado diagram in supplementary Figure 1 shows the main variables that influenced the results. All other sensitivity analyses (within the specified ranges) did not affect the results. If the probability of receiving chemotherapy in the low-risk Rs category increased to $50 \%$ from $0 \%$, then the ICER was approximately $\$ 21,299$ per QALY gained (the 21-gene RS assay strategy was more costly and more effective). If the probability of being in the low-risk Rs category decreased to 0.39 from 0.57 , the 21 -gene Rs assay strategy was dominated by current practice. Lastly, if the probability of receiving chemotherapy in the current practice arm decreased to 0.64 from 0.79 , the ICER was $\$ 2,159$ per QALY gained.

\section{DISCUSSION}

We found that the 21-gene Rs assay strategy could be a costeffective option for Ontario patients with LN-positive (1-3 LNS), ER-positive, HER2-negative early вCa. Many costeffectiveness studies have been conducted for LN-negative patients ${ }^{10,11,13,14,16,41}$. A number of studies found that the 21-gene Rs assay is primarily a cost-effective option (that is, the ICER falls below the willingness-to-pay threshold $)^{11,13,14,41}$; a few found that the 21-gene Rs assay is not cost-effective for the LN-negative population ${ }^{10,16}$.

Studies involving patients with LN-positive вса have been conducted in various countries, and most have determined that the 21-gene Rs assay strategy might be a costeffective option. To our knowledge, our Canadian costutility analysis is the only one focused on 1-3 LN-positive, ER-positive, HER2-negative BCa. Of two cost-utility studies conducted in Canada ${ }^{14,16}$, the first ${ }^{14}$ examined the costs and effects of the 21-gene Rs assay from the perspective of the Canadian health care payer over a 25 -year time horizon. The population consisted of patients 50 years of age with LN-positive, endocrine-sensitive вса. The number of LNS was not specified. The results indicated that the 21-gene RS assay cost $\$ 864$ more and led to 0.06 QALYs gained (ICER: $\$ 14,844$ per QALY gained). All 1-way sensitivity analyses were 
TABLE III Expected costs, quality-adjusted life-years (QALYs), lifeyears, and incremental cost effectiveness ratios (ICERs)

\begin{tabular}{lcc}
\hline \multicolumn{1}{c}{ Variable } & \multicolumn{2}{c}{ Practice type } \\
\cline { 2 - 3 } & Current & With 21-gene assay \\
\hline Discounted & \\
\hline Total expected cost (\$) & 54,502 & 54,070 \\
\hline Incremental cost (\$) & & -432 \\
\hline Total expected QALYs & 12.11 & 12.33 \\
\hline Incremental QALYs & & 0.22 \\
\hline Total expected life-years & 16.02 & 16.20 \\
\hline Incremental life-years & & 0.18 \\
\hline ICER & & Dominant \\
\hline Undiscounted & & 62,355 \\
\hline Total expected cost (\$) & 62,875 & -520 \\
\hline Incremental cost (\$) & & 14.60 \\
\hline Total expected QALYs & 14.33 & 0.27 \\
\hline Incremental QALYs & & 19.17 \\
\hline Total expected life-years & 18.93 & 0.24 \\
\hline Incremental life-years & & Dominant \\
\hline ICER & & \\
\hline
\end{tabular}

within the $\$ 50,000$-per-QALY willingness-to-pay threshold (ICER: \$6,199-\$14,297). That study took into consideration drug costs associated with 2 chemotherapy regimens (FEC100 and FEC-D). The cost per regimen was higher in the present study because the costs of the treatment regimen, the care associated with chemotherapy, and granulocyte colony-stimulating factors were included. The present study was therefore more comprehensive in its costing approach. Also, the other cost-utility study assumed that, after Rs stratification, chemotherapy use would be $7 \%, 70 \%$, and $92 \%$ for the low-risk, intermediate-risk, and high-risk Rs categories respectively. In contrast, our study assumed that no patients in the low-risk Rs category would receive adjuvant chemotherapy and that $100 \%$ of patients in the high-risk Rs category would.

The second Canadian cost-utility study ${ }^{16}$ examined the costs and effects of using the 21-gene Rs assay strategy over the lifetime of a patient diagnosed with early-stage ER-positive or progesterone receptor-positive, axillary LN-positive (1-3 LNS) BCa. It found that in postmenopausal women, the 21-gene Rs assay strategy cost $\$ 36.20$ more and led to 0.08 QALYS gained (ICER: \$464 per QALY gained). The sensitivity analysis revealed that, if fewer than $36 \%$ of the women in the intermediate-risk Rs group received adjuvant chemotherapy, then the 21-gene Rs assay led to a negative cost and effect. Their model differs from ours in that they also modelled local recurrence, a second primary вса, and remission with or without chemotherapy-associated serious adverse events. For the chemotherapy-associated adverse events, they considered 8 different diagnoses that resulted in hospitalizations. The types of serious adverse

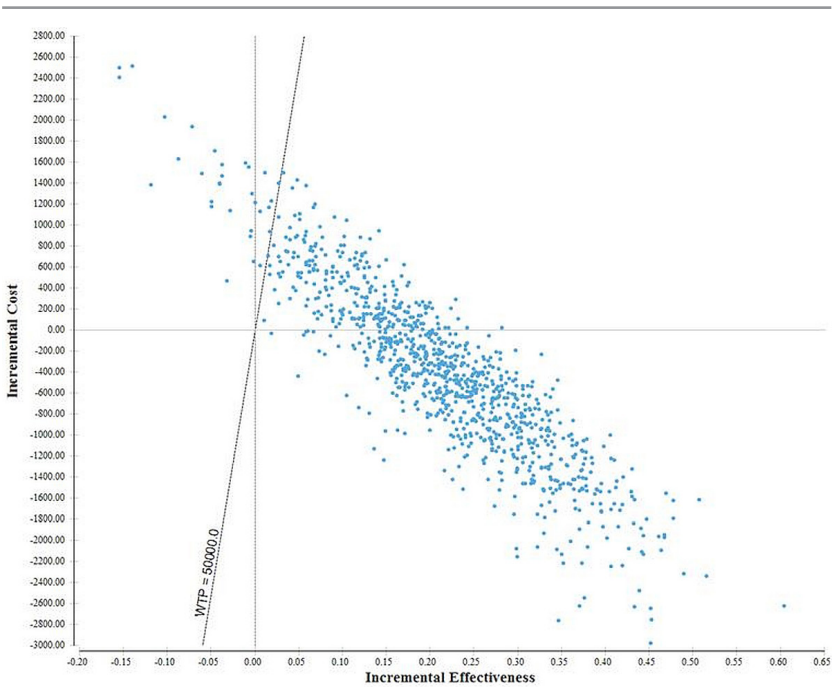

FIGURE 2 Cost-effectiveness plane, with 10,000 simulated incremental cost-effectiveness ratios from probabilistic analysis. WTP $=$ willingness to pay.

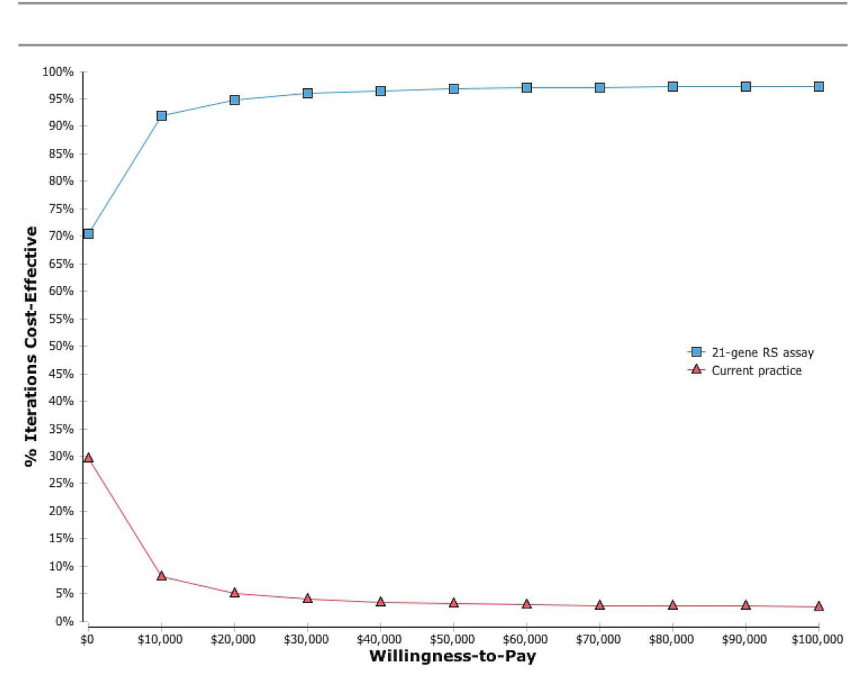

FIGURE 3 Cost-effectiveness acceptability curve. RS = Recurrence Score (Oncotype Dx: Genomic Health, Redwood City, CA, U.S.A.).

events considered were not reported in the publication. The treatment regimens that the authors considered also differed slightly from ours. The costs of their chemotherapy regimens were lower than the costs of ours. (They might not have included the costs associated with nursing and pharmacy time, a peripherally inserted central catheter, physician visits, and granulocyte colony-stimulating factor). Our study adds to the literature given that we used-and made explicit-detailed costs of the chemotherapy regimens.

Three studies conducted in the United States and the United Kingdom also considered the patient population considered in the present work ${ }^{9,15,42}$. Chandler et al. ${ }^{42}$ found that, compared with current clinical practice and taking a health care payer perspective, the 21-gene Rs assay strategy resulted in an ICER of $\$ 188,125$ per QALY gained. The results were most sensitive to test accuracy and utilities. With perfect test accuracy, the cost-effectiveness ratio was $\$ 28,947$ per 
QALY. If the utilities took into consideration the effect on the patient of decreased worry by receiving information about recurrence risk, the ICER was \$58,431 per QALY. Vanderlaan et al. ${ }^{15}$ examined the cost-effectiveness of the 21-gene RS assay strategy from a health care payer perspective over a 30-year time horizon. That study separated patients in the 21-gene Rs assay arm into low-risk and high-risk Rs categories. The results indicated that the intervention was less costly than current practice (\$384 less) and more effective (0.127 QALYs gained). The intervention dominated current practice. The sensitivity analysis revealed that if the proportion of tested patients who received chemotherapy after assay testing decreased to $42 \%$ from $54 \%$, then the intervention resulted in even more cost savings. One study from the United Kingdom examined the same patient population from the perspective of the health care payer over a lifetime horizon ${ }^{9}$. That study stratified patients into low-risk and high-risk Rs categories. The results revealed a mean incremental cost of $£ 860$ and incremental effectiveness of 0.16 QALYS gained (ICER: $£ 5,529$ ). The results were sensitive to the price of the 21-gene Rs assay, the model time horizon, the relative risk of CHF, quality of life while on chemotherapy, and Rs cut-offs for low-risk and high-risk. It is difficult to compare our overall results with the results from that study, given that its Rs stratification omitted the intermediate-risk Rs category.

\section{Strengths and Limitations}

The major strength of our study is that most of the data were obtained from published Canadian sources and reflect current practice. That approach makes our model applicable to the Ontario setting and potentially helpful for guiding practice in the province. As well, our model takes into consideration current treatment regimens within the Canadian setting. We addressed most of the modelling concerns reported in a systematic review of cost-effectiveness analyse of the 21-gene Rs assay ${ }^{43}$. Specifically, we considered both the short-term and long-term toxicities associated with chemotherapy; we selected a diagnosis age of 60 years, because that is the average age of patients presenting with вса; and we assumed that that patients in the low-risk Rs group had the same risk of distant recurrence whether they were treated with adjuvant chemotherapy or not.

Our study has a number of limitations to highlight. First, because of a lack of published data, it did not consider local recurrence. Having that information might make the 21-gene Rs assay strategy look even more economically attractive. Second, the cost of the disease-free health state might have been underestimated given that the costs were obtained from a study that reported costs for women diagnosed with вса in $1995^{33}$. Third, our model did not include the cost of antiemetic drugs to treat nausea and vomiting. Adding the cost of those drugs would make the 21-gene assay strategy more economically attractive. Fourth, a number of assumptions were made that might have influenced the findings. For example, the risks of recurrence for patients in the low-risk Rs category receiving and not receiving chemotherapy were assumed to be the same. In addition, the risk of recurrence became zero after 20 years, and the risks of CHF and leukemia occurred only during years 1-7 after chemotherapy. Nevertheless, those assumptions were made based on existing literature and were confirmed by clinicians to be clinically appropriate. Lastly, because our model was Ontario-specific, the generalizability of the findings might be limited to settings with a similar context.

It is important to note that, although вca recurrence with chemotherapy was not shown in the 1-way sensitivity analysis to have a significant effect on the results (within the clinically plausible ranges), the results could change in favour of current practice depending on the method used for estimation of recurrence. The recurrence rates used in our study were obtained for each Rs risk category and for LN-positive women ${ }^{25}$. A study by Pan et al. ${ }^{44}$ of вса recurrence in women with ER-positive BCa and 1-3 positive LNs reported that the annual rate of distant recurrence was $2.2 \%$ in year 1 and $1.8 \%$ in year 20 . We could not directly compare their estimates with the estimates from Albain et al. ${ }^{25}$, because Pan et al. did not separate their estimates by $\mathrm{Rs}$ risk category.

\section{CONCLUSIONS}

The 21-gene Rs assay was found to be an economically attractive option compared with no 21-gene Rs assay in women with LN-positive (1-3 LNS), ER-positive, HER2negative вса in Ontario, given certain model assumptions. Those findings might be of considerable interest to policymakers and health care providers in their decision-making process for personalized medicine for вса patients in similar settings.

\section{ACKNOWLEDGMENTS}

This study was supported by funding from Genomic Health Ltd. The paper reflects the views of the authors. No restrictions were set by the sponsor.

\section{CONFLICT OF INTEREST DISCLOSURES}

We have read and understood Current Oncology's policy on disclosing conflicts of interest, and we declare the following interests: funding for this study was received by Genomic Health Ltd. However, the research was conducted independently of Genomic Health Ltd. AE received funding from Genomic Health Ltd. for a decision study in which she was the principal investigator. ST received funding from Genomic Health Ltd. for a decision study in which she was a co-investigator and also fellowship support from Genomic Health Ltd. MT received funding from Genomic Health Ltd. for a decision study in which she was a co-investigator. IT received fees as an advisory board member for Teva Pharmaceuticals. LM, KWC, HS, and WI have no conflicts of interest to disclose.

\section{AUTHOR AFFILIATIONS}

*Centre for Excellence in Economic Analysis Research, St. Michael’s Hospital, `Sunnybrook Odette Cancer Centre, ${ }^{\ddagger}$ Cancer Care Ontario, ${ }^{\S}$ Canadian Centre for Applied Research in Cancer Control, and "Institute of Health Policy, Management and Evaluation, University of Toronto, Toronto, ON.

\section{REFERENCES}

1. Canadian Cancer Society. Breast Cancer Statistics [Web page]. Toronto, ON: Canadian Cancer Society; n.d. [Available at: https://www.cancer.ca/en/cancer-information/ cancer-type/breast/statistics/?region=on; cited 1 January 2018] 
2. Carlson RW, Allred DC, Anderson BO, et al. on behalf of the NCCN Breast Cancer Clinical Practice Guidelines Panel. Breast cancer: clinical practice guidelines in oncology. J Natl Compr Cancancer Netw 2009;7:122-92.

3. Eisen A, Fletcher GG, Gandhi S, et al. on behalf of the members of the Early Breast Cancer Systemic Therapy Consensus Panel. Optimal systemic therapy for early breast cancer in women: a clinical practice guideline. Curr Oncol 2015;22(suppl 1):S67-81.

4. de Boer RH, Baker C, Speakman D, Chao CY, Yoshizawa C, Mann GB. The impact of a genomic assay (Oncotype Dx) on adjuvant treatment recommendations in early breast cancer. Med J Aust 2013;199:205-8.

5. Eiermann W, Rezai M, Kümmel S, et al. The 21-gene Recurrence Score assay impacts adjuvant therapy recommendations for ER-positive, node-negative and node-positive early breast cancer resulting in a risk-adapted change in chemotherapy use. Ann Oncol 2013;24:618-24.

6. Oratz R, Kim B, Chao C, et al. Physician survey of the effect of the 21-gene Recurrence Score assay results on treatment recommendations for patients with lymph node-positive, estrogen receptor-positive breast cancer.JOncol Pract 2011;7:94-9.

7. Torres S, Trudeau M, Gandhi S, et al. Prospective evaluation of the impact of the 21-gene Recurrence Score assay on adjuvant treatment decisions for women with node-positive breast cancer in Ontario, Canada. Oncologist 2018;23:768-75.

8. Petkov VI, Miller DP, Howlader N, et al. Breast-cancer-specific mortality in patients treated based on the 21-gene assay: a SEER population-based study. NPJ Breast Cancer 2016;2:16017. [Erratum in: NPJ Breast Cancer 2018;4:17]

9. Hall PS, McCabe C, Stein RC, Cameron D. Economic evaluation of genomic test-directed chemotherapy for early-stage lymph node-positive breast cancer. J Natl Cancer Inst 2012;104:56-66.

10. Tsoi DT, Inoue M, Kelly CM, Verma S, Pritchard KI. Costeffectiveness analysis of Recurrence Score-guided treatment using a 21-gene assay in early breast cancer. Oncologist 2010;15:457-65.

11. Paulden M, Franek J, Pham B, Bedard PL, Trudeau M, Krahn M. Cost-effectiveness of the 21-gene assay for guiding adjuvant chemotherapy decisions in early breast cancer. Value Health 2013;16:729-39.

12. Reed SD, Dinan MA, Schulman KA, Lyman GH. Costeffectiveness of the 21-gene Recurrence Score assay in the context of multifactorial decision making to guide chemotherapy for early-stage breast cancer. Genet Med 2013;15:203-11.

13. Blohmer JU, Rezai M, Kümmel S, et al. Using the 21-gene assay to guide adjuvant chemotherapy decision-making in early-stage breast cancer: a cost-effectiveness evaluation in the German setting. J Med Econ 2013;16:30-40.

14. Lamond NW, Skedgel C, Rayson D, Lethbridge L, Younis T. Cost-utility of the 21-gene Recurrence Score assay in node-negative and node-positive breast cancer. Breast Cancer Res Treat 2012;133:1115-23.

15. Vanderlaan BF, Broder MS, Chang EY, Oratz R, Bentley TG. Cost-effectiveness of 21-gene assay in node-positive, earlystage breast cancer. Am J Manag Care 2011;17:455-64.

16. Hannouf MB, Xie B, Brackstone M, Zaric GS. Cost effectiveness of a 21-gene Recurrence Score assay versus Canadian clinical practice in post-menopausal women with early-stage estrogen or progesterone-receptor-positive, axillary lymph-node positive breast cancer. Pharmacoeconomics 2014;32:135-47.

17. Younis T, Rayson D, Thompson K. Primary G-CSF prophylaxis for adjuvant TC or FEC-D chemotherapy outside of clinical trial settings: a systematic review and meta-analysis. Support Care Cancer 2012;20:2523-30.
18. Roché H, Fumoleau P, Spielmann M, et al. Sequential adjuvant epirubicin-based and docetaxel chemotherapy for node-positive breast cancer patients: the FNCLCC PACS 01 trial. J Clin Oncol 2006;24:5664-71.

19. Goldhar HA, YanAT, KoDT, etal. The temporal risk of heartfailure associated with adjuvant trastuzumab in breast cancer patients: a population study. J Natl Cancer Inst 2016;108:pii:djv301.

20. Torres S, Trudeau M, Eisen A, Earle CC, Chan KKW. Adjuvant taxane-based chemotherapy for early stage breast cancer: a real-world comparison of chemotherapy regimens in Ontario. Breast Cancer Res Treat 2015;152:137-45.

21. Jones S, Holmes FA, O'Shaughnessy J, et al. Docetaxel with cyclophosphamide is associated with an overall survival benefit compared with doxorubicin and cyclophosphamide: 7-year follow-up of US Oncology research trial 9735. J Clin Oncol 2009;27:1177-83.

22. Citron ML, Berry DA, Cirrincione C, et al. Randomized trial of dose-dense versus conventionally scheduled and sequential versus concurrent combination chemotherapy as postoperative adjuvant treatment of node-positive primary breast cancer: first report of Intergroup trial C9741/Cancer and Leukemia Group B trial 9741. JClin Oncol 2003;21:1431-9.

23. Frazier CG, Alexander KP, Newby LK, et al. Associations of gender and etiology with outcomes in heart failure with systolic dysfunction. A pooled analysis of 5 randomized control trials. J Am Coll Cardiol 2007;49:1450-8.

24. Hulegårdh E, Nilsson C, Lazarevic V, et al. Characterization and prognostic features of secondary acute myeloid leukemia in a population-based setting: a report from the Swedish Acute Leukemia Registry. Am J Hematol 2015;90:208-14.

25. Albain KS, Barlow WE, Shak S, et al. on behalf of the Breast Cancer Intergroup of North America. Prognostic and predictive value of the 21-gene Recurrence Score assay in postmenopausal women with node-positive, oestrogen-receptorpositive breast cancer on chemotherapy: a retrospective analysis of a randomised trial. Lancet Oncol 2010;11:55-65.

26. Mouridsen $\mathrm{H}$, Gershanovich M, Sun Y, et al. Phase III study of letrozole versus tamoxifen as first-line therapy of advanced breast cancer in postmenopausal women: analysis of survival and update of efficacy from the International Letrozole Breast Cancer Group. J Clin Oncol 2003;21:2101-9.

27. Statistics Canada. Table 7b: Complete life table, females, Ontario, 2009 to 2011 [Web resource]. Ottawa, ON: Statistics Canada; 2015. [Available at: https://www150.statcan.gc.ca/n1/pub/84537-x/2013005/tbl/tbl7b-eng.htm; cited 1 January 2018]

28. Canadian Agency for Drugs and Technologies in Health (САDTH). Guidelines for the Economic Evaluation of Health Technologies: Canada. 4th ed. Ottawa, ON: CADTH; 2017.

29. Briggs A, Schulpher M, Claxton K. Decision Modelling for Health Economic Evaluation. New York, NY: Oxford University Press; 2006.

30. Lidgren M, Wilking N, Jönsson B, Rehnberg C. Health related quality of life in different states of breast cancer. Qual Life Res 2007;16:1073-81.

31. Kirsch J, McGuire A. Establishing health state valuations for disease specific states: an example from heart disease. Health Econ 2000;9:149-58.

32. Barr R, Furlong W, Henwood J, et al. Economic evaluation of allogeneic bone marrow transplantation: a rudimentary model to generate estimates for the timely formulation of clinical policy. J Clin Oncol 1996;14:1413-20.

33. Will BP, Berthelot JM, Le Petit C, Tomiak EM, Verma S, Evans WK. Estimates of the lifetime costs of breast cancer treatment in Canada. Eur J Cancer 2000;36:724-35.

34. de Oliveira C, Pataky R, Bremner KE, et al. Phase-specific and lifetime costs of cancer care in Ontario, Canada. BMC Cancer 2016;16:809. 
35. Ontario, Ministry of Health and Long-Term Care (MOHLTC). Ontario Schedule of Benefits for Physician Services Under the Health Insurance Act. Toronto, ON: MOHLTC; 2015.

36. Lathia N, Mittmann N, DeAngelis C, et al. Evaluation of direct medical costs of hospitalization for febrile neutropenia. Cancer 2010;116:742-8.

37. Lachaine J, Yelle L, Kaizer L, Dufour A, Hopkins S, Deuson R. Chemotherapy-induced emesis: quality of life and economic impact in the context of current practice in Canada. Support Cancer Ther 2005;2:181-7.

38. Younis T, Rayson D, Skedgel C. The cost-utility of adjuvant chemotherapy using docetaxel and cyclophosphamide compared with doxorubicin and cyclophosphamide in breast cancer. Curr Oncol 2011;18:e288-96.

39. de Oliveira C, Bremner KE, Pataky R, et al. Understanding the costs of cancer care before and after diagnosis for the 21 most common cancers in Ontario: a population-based descriptive study. CMAJ Open 2013;1:E1-8.

40. Statistics Canada. Consumer price index, annual average, not seasonally adjusted [Web page, Ontario]. Ottawa, ON:
Statistics Canada; 2018. [Available at: https://www150. statcan.gc.ca/t1/tbl1/en/tv.action?pid $=1810000501 \&$ pick Members\%5B0\%5D=1.14; cited 1 January 2018]

41. Hornberger J, Lyman GH, Chien R. Economic implications of 21-gene Recurrence Score assay: US multicenter experience. J Clin Oncol 2010;28:e382. [Comment on: Lo SS, Mumby PB, Norton J, et al. Prospective multicenter study of the impact of the 21-gene Recurrence Score assay on medical oncologist and patient adjuvant breast cancer treatment selection. JClin Oncol 2010;28:1671-6]

42. Chandler Y, Schechter CB, Jayasekera J, et al. Cost effectiveness of gene expression profile testing in community practice. J Clin Oncol 2018;36:554-62.

43. Wang SY, Dang W, Richman I, Mougalian SS, Evans SB, Gross CP. Cost-effectiveness analyses of the 21-gene assay in breast cancer: systematic review and critical appraisal. JClin Oncol 2018;36:1619-27.

44. Pan H, Gray R, Braybrooke J, et al. 20-Year risks of breastcancer recurrence after stopping endocrine therapy at 5 years. N Engl J Med 2017;377:1836-46. 